Gibson, Stephen ORCID:

https://orcid.org/0000-0002-5648-7669 (2013) Milgram's obedience experiments: A rhetorical analysis. British Journal of Social Psychology, 52 (2). pp. 290-309.

Downloaded from: http://ray.yorksj.ac.uk/id/eprint/594/

The version presented here may differ from the published version or version of record. If you intend to cite from the work you are advised to consult the publisher's version: http://dx.doi.org/10.1111/j.2044-8309.2011.02070.x

Research at York St John (RaY) is an institutional repository. It supports the principles of open access by making the research outputs of the University available in digital form. Copyright of the items stored in RaY reside with the authors and/or other copyright owners. Users may access full text items free of charge, and may download a copy for private study or non-commercial research. For further reuse terms, see licence terms governing individual outputs. Institutional Repository Policy Statement

\title{
RaY
}

Research at the University of York St John

For more information please contact RaY at ray@yorksj.ac.uk 


\section{Milgram's obedience experiments: A rhetorical analysis}

\section{Stephen Gibson}

${ }^{1}$ York St John University

British Journal of Social Psychology

${ }^{*}$ Requests for reprints should be addressed to Stephen Gibson, Faculty of Health \& Life Sciences, York St John University, Lord Mayor's Walk, York, YO31 7EX, UK (e-mail: s.gibson@yorksj.ac.uk).

Acknowledgments: I would like to thank two anonymous reviewers for their comments on an earlier version of this paper. The project on which this article is based was funded by a grant from the Nuffield Foundation (SGS/36502). I would like to acknowledge the invaluable assistance of Cynthia Ostroff and her colleagues at Yale University's Manuscripts and Archives Services. The article presents extracts of material transcribed from audio tapes of participants in conditions 02 and 20 of the Milgram Obedience Experiment. Permission is granted by Alexandra Milgram. 
Milgram's obedience experiments: A rhetorical analysis 


\begin{abstract}
The present paper outlines a perspective on Milgram's obedience experiments informed by rhetorical psychology. This perspective is demonstrated through a qualitative analysis of audio recordings and transcripts from two of Milgram's experimental conditions: 'voicefeedback' and 'women as subjects'. Analysis draws attention to the way in which participants could draw the experimenter into a process of negotiation over the continuation of the experimental session, something which could lead to quite radical departures from the standardized experimental procedure, and points to the ineffectiveness of Milgram's fourth prod ('You have no other choice, you must go on'). These observations are discussed in terms of their implications for theory and research on dis/obedience, with a specific focus on the concepts of choice and agency and the nature and meaning of dis/obedience.
\end{abstract}

KEYWORDS: Discourse analysis; Milgram; Obedience; Rhetoric; Social influence. 


\section{$\underline{\text { Milgram's obedience experiments: A rhetorical analysis }}$}

It hardly needs to be stated that Milgram's (1963, 1965a, 1974) obedience experiments are amongst the most influential and controversial studies in psychology. They continue to stimulate a diverse range of empirical work (e.g. Burger, 2009; Burger, Girgis \& Manning, 2011; Dambrun \& Vatiné, 2010; Packer, 2008; Reeder, Monroe \& Pryor, 2008), conceptual debate (e.g. De Vos, 2009; Haslam \& Reicher, 2007; Passini \& Morselli, 2009; Reicher \& Haslam, 2011) and historical scholarship (Blass, 2004, 2009; Benjamin \& Simpson, 2009; Russell, 2009, 2011), and are still regularly cited in discussions of atrocities and abuses both historical and contemporary (e.g. Fiske, Harris \& Cuddy, 2004; Lankford, 2009; Miller, 2004). In this context it may perhaps seem that there is little new to say about the original experiments themselves, but I want to argue that a central aspect of Milgram's obedience experiments has been largely neglected as a conventional image of the studies has crystallised and been transmitted to successive generations of social psychologists and the wider public. The present paper concerns itself with the interactions that took place in Milgram's obedience laboratory, with a specific focus on the use of rhetoric by the participants and by the experimenter, played so effectively by Milgram's confederate, John Williams.

\section{The obedience experiments}

Of Milgram's (1974) many experimental conditions, perhaps the most widely known are those which take a form similar to that portrayed at greatest length in his film, Obedience (Milgram, 1965b). The basic procedure in these conditions involved a participant arriving at a laboratory, ostensibly to take part in a study concerning the effects of punishment on learning, and finding themselves caught up in a situation in which they took the role of 'teacher' in a memory task. This role required them to use what they were led to believe was 
an electric shock generator to inflict harm on another person, the 'learner', who they had seen being strapped into a chair in an adjacent room. The learner provided answers to the memory test administered by the teacher, but as the experimental session went on the learner returned more and more incorrect answers, necessitating the administration of shocks increasing in $15 \mathrm{v}$ increments, culminating in a shock of 450v. As the shocks increased, the learner first began to cry out in apparent pain, and then following the 150v shock he demanded to be released. Following this, the learner's expressions of distress intensified, before he refused to answer any further questions following the 300v shock. After the 330v shock, the learner's protests ceased (Milgram, 1974).

Unbeknownst to the participants, however, the learning experiment was simply a cover story, and the real aim of the study was to assess participants' willingness to obey authority. No harm was actually caused to the learner, who was in fact a confederate, and his protests had been pre-recorded. Where participants appeared to be reluctant to continue, the experimenter used a series of four prods to instruct them to go on administering the electric shocks. These prods, identified by Miller, Collins and Brief $(1995$, p. 3) as 'the most important methodological feature in Milgram's paradigm', were as follows:

Prod 1: Please continue, or, Please go on.

Prod 2: The experiment requires that you continue.

Prod 3: It is absolutely essential that you continue.

Prod 4: You have no other choice, you must go on.

(Milgram, 1974, p. 21, italics in original) In addition, the experimenter could use two extra prods to answer specific queries from participants as appropriate. These were: 'Although the shocks may be painful, there is no permanent tissue damage, so please go on' (ibid.) and 'Whether the learner likes it or not, you must go on until he has learned all the word pairs correctly. So please go on' (ibid., p. 22). 
The four main prods were to be used in sequence, starting anew from prod 1 for each separate attempt at defiance, and only when all of these prods had been used was an experimental session discontinued.

Milgram used two forms of dependent measure, both derived from the shocks administered: the maximum shock delivered by participants, and a categorical variable, with participants recorded as either being obedient or defiant. Obedience was operationalized as the use of the 450v switch on the shock generator, with participants who successfully ended their session at any point prior to pushing this lever being coded as defiant. When conducted at Yale University, this basic procedure - sometimes with slight modifications - yielded obedience rates of 50\% (condition 6 in Milgram, 1974), 62.5\% (condition 2), and 65\% (conditions 5 and 8). When the location was switched to an office building in the town of Bridgeport (condition 10), with no apparent link to Yale, it yielded an obedience rate of $47.5 \%$.

Although it is difficult to do justice to the nuances of Milgram's work - and in particular to the many other experimental conditions based on this procedure - in such a short description, this summary nevertheless draws attention to some important features of Milgram's procedure that will be discussed further below. However, before moving onto the main thrust of my argument, it is first necessary to discuss briefly some attempts to provide a theoretical account of Milgram's findings.

\section{Obedience: Theoretical frameworks}

Milgram's (1974) own attempt to theorise destructive obedience revolved around the concept of the agentic state. Briefly, this account suggested that obedience relied upon people ceasing to view themselves as autonomous social actors, instead entering a psychological state in which their actions were controlled by some other agent. However, 
numerous authors have noted that Milgram's account is at best only partially supported by the available evidence (e.g. Blass, 2004; Miller, 1986), and subsequent attempts to develop a theoretical apparatus to explain Milgram's findings have been similarly afflicted. Indeed, Miller (2009, p. 21) recently suggested that in discussions of Milgram’s work, ‘[p]lausible ideas ... are rampant, but somewhat vague and always numerous.'

The contrary perspectives apparent in attempts to develop a theoretical framework to explain Milgram's findings can be illustrated through a brief discussion of two such endeavours. Nissani (1990, p.1385) has argued that the limitations of the human cognitive system mean that 'people cannot be counted on ... to realize that a seemingly benevolent authority is in fact malevolent, even when they are faced with overwhelming evidence that this authority is indeed malevolent'. In contrast, Russell (2009, p. 132) suggests that Milgram's concept of the agentic state should be replaced by what he terms a state of autonomous denial: 'a state of mind in which subjects knew that they were most responsible for their own actions, but sensed the existence of opportunities that might enable them to avoid a confrontation with the experimenter and evade feeling and/or appearing personally responsible for electrocuting the learner.' These contrasting attempts to account for Milgram's findings thus differ on whether obedient participants in fact realised that what they were doing was morally problematic. In Nissani's account, the limitations of human thinking preclude a straightforward shift from viewing the experimenter as a fundamentally benevolent figure, whereas in Russell's account the participants are fully aware of the morally opprobrious nature of their actions, but draw on a series of psychological mechanisms to enable them to deny their responsibility.

In contrast to such attempts to develop an all-encompassing theory of destructive obedience, the present paper's aims are more modest. It is suggested that attempts to theorize the nature of obedience have tended to neglect an important aspect of the Milgram 
experiments - the actual interactions between participant and experimenter. The present paper focuses in particular on the rhetorical character of these interactions in order to shift the focus of attention from the question of why many participants obeyed the experimenter, to how a substantial minority of them disobeyed the experimenter. Many authors have pointed out that levels of disobedience in Milgram's study have been generally neglected (e.g. Packer, 2008; Parker, 2007). The present study seeks to develop this observation by noting that not only did some participants successfully extricate themselves from the experimental situation, but that they did so by negotiating and arguing their way out of it. In short, they engaged in the creative and flexible use of rhetoric in order to resist the authority of the experimenter. As will become apparent, once we begin to address this question, other avenues of inquiry are opened up, not least amongst which is the rhetorical nature of the experimenter's contributions to the interactions in the experimental sessions.

\section{Rhetorical psychology}

The theoretical and methodological framework for the present analysis is provided by rhetorical psychology (Billig, 1991, 1996; Billig et al., 1988), a member of the wider family of discourse analytic methods (e.g. Potter, 2007; Potter \& Wetherell, 1987). Whilst not wishing to gloss over some important differences between these approaches, they adopt a common emphasis on the textual analysis of discursive materials within a broadly social constructionist epistemological framework (Potter, 1996; Potter \& Hepburn, 2008)

The specific focus of rhetorical psychology is on the identification of discursive strategies and lines of argument in discourse. By paying close attention to the way in which language is used, it aims to specify the ways in which patterns of argumentation are related both to the immediate discursive context, and to the wider themes of cultural commonsense. Billig and his colleagues (Billig, 1991, 1996; Billig et al, 1988) have used this approach to re- 
specify a number of core social psychological constructs - such as attitudes, categorization, and representations - as fundamentally rhetorical. In this respect, the key point of departure for a rhetorical psychological analysis is the extent to which those constructs typically treated as relatively static psychological objects can be seen to be flexibly worked up by speakers in the process of argumentation. In emphasising the centrality of argumentation, rhetorical psychology is not suggesting that we need only to explore contexts that might appear to be explicitly adversarial, but that the requirement to buttress claims and account for one's practice is fundamental to even the most mundane areas of social life. Crucially, Billig (1996) noted that every statement of a position, claim to truth, or formulation of an account carries with it the possibility of its own refutation, for the construction of any argument is a tacit acknowledgement that alternate propositions are possible. Drawing on classical rhetorical scholarship, Billig termed these the logos and anti-logos of argumentation. For every assertion (logos) there is the possibility of counter assertion (anti-logos)

The broad field of discursive and rhetorical psychology has been characterized by extensive debate over theory and method, with the level of interactional detail to be incorporated into analysis being one of the key points of disagreement (see e.g. Billig, 1999; Schegloff, 1997, 1998, 1999; Wetherell, 1998). For some - notably those influenced by conversation analysis - a focus on the details of interaction takes analytic priority. For others, however, such an injunction to stick closely to the minute details of talk-in-interaction risks neglecting the way in which any particular moment of talk is situated within a wider discursive context.

The present paper is not the place to rehearse these debates at length, but it should be noted that my analysis here draws on some of the insights of the more fine-grained approaches to discourse analysis, whilst attempting to retain a wider view of the situation of particular discursive episodes within the context of the whole experimental encounter. Such 
an attempt to plot a course between two extremes can, of course, run the risk of failing to satisfy advocates of either. However, it is notable that the original discourse analytic project of Gilbert and Mulkay (1984, p. 17) was articulated as occupying 'a middle ground' which constituted "part of an eclectic movement toward the systematic investigation of discourse in all areas of social life.' Indeed, one of the appealing aspects of much early discourse analytic work in social psychology was its attempts to draw together a range of disparate traditions into a coherent whole. In adopting the rhetorical psychological approach here, then, my intention is to signal a need to engage in analysis which - whatever the risks of 'falling between two stools' - attempts to marshal the analytic resources of both macro and microfocussed approaches.

In order to illustrate the implications of this approach for our understanding of the Milgram experiments, the present article draws on the findings of a secondary analysis of materials held in the Stanley Milgram Papers at Yale University. This archive holds audio recordings from most of Milgram's experimental sessions. Milgram (1974) presented many transcribed excerpts from the recordings, but given that at the time he was writing there were few established and generally accepted techniques for qualitative analysis within psychology, it is hardly surprising that rather than presenting any form of systematic qualitative analysis, Milgram used these excerpts essentially as anecdotal examples. For instance, Milgram introduces one participant, who he identifies as a 'Professor of Old Testament', and reproduces the following extract from a transcript of this participant's experimental session, which occurred after the participant had reached 150 volts on the shock generator:

EXPERIMENTER: It's absolutely essential to the experiment that we continue.

SUBJECT: I understand that statement, but I don't understand why the experiment is placed above this person's life. 
EXPERIMENTER: There is no permanent tissue damage.

SUBJECT: Well, that's your opinion. If he doesn't want to continue, I'm taking orders from him.

EXPERIMENTER: You have no other choice, sir, you must go on.

SUBJECT: If this were Russia maybe, but not in America.

(Milgram, 1974, p. 48)

After this exchange, Milgram reports that the experimental session was discontinued, and goes on to point to the way in which the participant 'initially justified his breaking off the experiment not by asserting disobedience but by asserting that he would then take orders from the victim' (ibid., p. 49). Although Milgram cautioned against taking the participants' words at face value, in the absence of a clear framework in which to conceptualize this exchange, Milgram's subsequent gloss can be read as treating the participant's justification as indicative of some underlying psychological process or event: 'Thus, he speaks of an equivalence between the experimenter's and the learner's orders and does not disobey so much as shifts the person from whom he will take orders' (ibid.). If we are to suggest that a genuine shift in the source of authority has taken place, we must take the participants' words at face value. When he says 'I'm taking orders from him', the character of the participant's actions must be seen as having undergone a significant change: Whereas previously he had been obeying the experimenter, now he obeys the learner.

In contrast, we might fruitfully conceptualise this utterance as part of a rhetorical strategy for extricating the participant from the experimental situation. Indeed, when we place the utterance in the context of the participant's whole speaking turn, we can begin to see how it is part of a more general rhetorical strategy of undermining the experimenter's authority. Significantly, the participant responds to the experimenter's 'There is no permanent tissue damage' prompt with a classic rhetorical move which functions to 
undermine the facticity of the experimenter's statement: He glosses what has been offered as a statement of fact as merely an opinion, and thereby challenges the experimenter's authority to pronounce on the physical effects of electric shocks. In providing such a reading of the transcript, we have no need to seek to identify whether the participant really thinks that the experimenter's statement about tissue damage is simply a matter of opinion, nor need we be concerned with whether the participant undergoes some sort of psychological shift from obeying the orders of the experimenter to obeying the participant. What is crucial is that these utterances perform a particular rhetorical function in the local context of their use. They enable the participant to subvert the experimenter's authority, and in so doing provide a potential 'way out' of the experimental situation.

As argued above, it is not surprising that Milgram did not develop the implications of such observations himself given that he was working prior to what some authors have termed 'the turn to language' in the social sciences (see e.g. Kroger \& Wood, 1998). However, given the developments in qualitative methodologies which have occurred since Milgram's work was published (e.g. Madill \& Gough, 2008; Rennie, Watson \& Monteiro, 2002), it is perhaps more notable that the continued recognition of the significance of Milgram's research has yet to stimulate secondary qualitative analysis of his data.

One partial exception to this is provided by Modigliani and Rochat (1995) who argued that the lack of clear understanding of Milgram's findings may be due to the neglect of interaction in the encounter between participant and experimenter. Specifically, they argue that, "[i]n the time between the initial command and the final outcome (obedient or defiant), subjects are engaged in a continuous social interaction with the authority, the victim, and any others who may be present. At particular moments this interaction itself may bring them closer to, or farther from, obedience' (Modigliani \& Rochat, 1995, p. 108). Modigliani and Rochat (1995, p. 113) developed a hypothesis that ' $[\mathrm{t}]$ he earlier in the procedure subjects 
begin to resist notably, the more likely they will be to end up defiant' (italics in original) and tested this through a content analysis of recordings of the Bridgeport condition (Milgram, 1974, experiment 10). Modigliani and Rochat found support for their hypothesis, with their analysis suggesting that the earlier a participant explicitly began to resist the experimenter's commands (e.g. by questioning him, or objecting to the experiment), the more likely they were ultimately to successfully break off their participation in the experiment.

Modigliani and Rochat's key contribution is to draw attention to the way in which participants could facilitate their disengagement from the experiment by challenging and questioning the experimenter at an early stage. In this respect, we might suggest that the key to defiance is to frame the encounters as occasions for rhetoric - those who began to engage in argument during the earlier stages of the experiment in effect set out their stall and began building their arguments for the cessation of the experiment much sooner than those who were more reticent. Although this emphasis on interaction in the Milgram experiments represents an important advance on some previous conceptual analyses, Modigliani and Rochat's perspective ultimately fails to fully engage with the rhetorical nature of the interactions, and, crucially, they are not concerned with either the content or structure of the actual arguments constructed by participants in their attempts to extricate themselves from the experiments. Finally, their analysis potentially misses the rhetorical character of the experimenter's utterances. Notably, Modigliani and Rochat suggest that the role of the experimenter is analogous to that of a parent seeking to impose their authority on a child: 'There is no effort to persuade - only to firmly remind subordinates of their well-known obligations' (p. 114). The present paper seeks to focus on these issues by exploring the use of rhetoric in two of Milgram's conditions. 
Conditions 02 and 20 make a particularly good starting point for the analysis of rhetoric in the Milgram experiments as they represent some of the best available 'baseline' data from the experiments. Condition 02 was labelled the 'Voice-Feedback' condition by Milgram (1974), and used the procedure described above. Condition 20, labelled 'Women as Subjects' and reported as experiment 8 by Milgram (1974), was the sole experimental condition in which women participated. ${ }^{1}$ This condition also used the basic procedure described above, although in addition the learner disclosed a mild heart condition as he was being strapped in to the chair, and subsequently referred to this in some of his protests.

As for most of Milgram's conditions, a range of materials from conditions 02 and 20 are held in the Stanley Milgram Papers at Yale University's Archives and Manuscripts Service. Data accessed for the present paper include 'subject files' for each participant, which consist of demographic information, completed post-experiment and follow-up questionnaires, as well as notes made on participants' performance during the experiment. Most importantly, however, the archives contain audio recordings of many of the experimental sessions, some of which also include the post-experiment debrief and interview, and a certain amount of pre- and post-experiment discussion amongst Milgram and his confederates. Although some recordings are missing from the archives, it was possible to access a total of 39 (out of 40) experimental sessions from condition 02, and 31 (also out of 40) from condition 20. These recordings were transcribed by the author in order to allow for a qualitative analysis of the rhetorical dynamics of the experimental sessions. ${ }^{2}$

Within the constraints of the present paper the empirical examples must necessarily be limited. Rather than reporting a full analysis of these data, the present discussion instead seeks to draw attention to two related aspects of the interactions. First, through the use of a case example from one particular participant in condition 02 , I want to explore how participants' rhetorical strategies could draw the experimenter away from the standardized 
script of the experiment. Second, I want to highlight the sorts of questions that this style of analysis might be used to address by attempting to settle a question concerning the effectiveness of the prods - and of one prod in particular - in eliciting obedience from the participants.

Rhetoric in the obedience lab: A case example

Condition 02 is part of the early proximity series of experiments initially reported in Milgram (1965a). Russell (2009) has suggested that the proximity series should perhaps have been treated as an extension of Milgram's pilot studies as he was yet to settle on the final standardized procedure. For present purposes it is notable that the flexibility that the yet-tobe finalized procedure affords the experimenter provides interesting material for the study of rhetoric in the obedience lab. Notably, this points to the importance of rhetoric in the experimenter's, as well as the participants', utterances.

These points can be illustrated through an extended example from experimental session 0208. As the participant seeks initially to place conditions on his continued participation in the experimental session, and ultimately to negotiate his way out of it, the experimenter seeks to elicit the continued compliance of the teacher. The exchange reported in the following extract begins with the teacher about to administer the $120 \mathrm{v}$ shock following an incorrect response:

\section{Extract 1a (Participant 0208)}

$1 \quad$ T: $\quad$ I'm going to administer a hundred and twenty

2 volts.

$3 \quad((\mathrm{SHOCK}))$

4 L: URGH! Hey these really hurt. 
6 T: I don't think I wanna, be a part of this anymore.

7

(2)

$8 \quad$ E: $\quad$ Please continue.

9 T: No.

10

11 E: It's absolutely essential that you go on.

12

(2)

13 T: Well if he says it's all right it's all right with me

14 will you ask him if he wants to go on?

$15 \quad(3)$

16 E: Whether the learner likes it or not er, we must

17 continue.

18 T: I wouldn't contin-

19 E: ((inaudible))-

20 T: I wouldn't continue without asking him.

21

(2)

22 E: As I explained to both er, er to him when you were

23 there, er although the shocks may be extremely

24 painful there is no permanent tissue damage.

25 T: Well I still th- I still don't want to go on unless he

26 says all right.

The participant's initial attempt to begin to extricate himself from the experiment is notable insofar as it consists not of a straightforward request to stop or a refusal to continue, but instead is framed as a report of his current thinking (1. 6: 'I don't think I wanna, be a part of 
this anymore). The way in which this functions to hedge the participant's initiation of an attempt to bring about the cessation of the experiment is perhaps not surprising given the potentially face-threatening act in which he is engaging. Indeed, many authors have noted that participants often seemed to go to great lengths to appear polite in the experiments (e.g. Milgram, 1974; Russell, 2009). In this respect, this opening attempt to negotiate the cessation of the session places the onus on the experimenter to respond in an appropriate manner. Of course, the experimenter does no such thing and instead uses the first prod (1. 8), which is met with a straightforward denial from the participant, followed by a long silence. The experimenter's subsequent use of prod 3 (1.11) occasions an interesting rhetorical manoeuvre from the teacher, who places a condition on his continued participation, namely that he will continue if the learner also wishes to continue (11. 13-14). The experimenter responds to this with an adapted version of one of the special prods (11. 16-17) which positions the learner's wishes as irrelevant to the continuation of the experiment. Following a re-statement of the participant's condition for continuation (1.20), the experimenter utilises a further special prod (11. 22-23), but neither this, nor the preceding prod, satisfies the condition placed by the participant, who re-states it again on lines 25-26.

We can thus begin to see how the experimenter's goal of eliciting obedience using the experimental prompts can be frustrated by a participant engaging in what Billig (1996) has termed 'witcraft'; the creative use of rhetoric to suit the demands of the particular argumentative context in which one finds oneself. The participant in this session has engaged the experimenter in a process of negotiation concerning the conditions for the continuation of the experiment. At this point, the experimenter looks to be defeated, having used what appears to be his most suitable pre-prepared rhetorical strategy against this particular argument (i.e. the special prod used on 11. 16-17), and we might expect a fairly swift procession through the final prod ('You have no other choice...') to be met with steadfast 
resistance from a participant stubbornly sticking to his argument. However, it is perhaps significant to note that in arriving at this point the experimenter has in fact missed out prod 2 ('The experiment requires that you continue'), moving instead from prod 1 (1.8) to prod 3 (1. 11) prior to the use of the two special prods. There thus appears to be more flexibility in the procedure than is typically assumed in most discussions of the Milgram experiments, something which is confirmed by the events which follow immediately after:

\section{Extract 1b (Participant 0208)}

32 E: He seems willing enough to go on so please

35 T: Wet, night, grass, duck, cloth. heard, and what sounds like a door shutting. From what follows it seems reasonable to to ask $\mathrm{L}$ if he wished to continue)) continue.
(52) ((During this time period movement can be presume that $\mathrm{E}$ went out of the room, ostensibly

Although it is difficult to be sure exactly what occurred at this point given the absence of visual information necessitated by the reliance on audio recordings, the experimenter breaks the silence with an attempt to reassure the teacher that the learner 'seems willing enough to go on'. This attempt to convince through an appeal to privileged insider information gained by virtue of an apparently back-stage consultation with the learner is successful in eliciting obedience from the teacher, who continues with the memory test and goes on to administer two further shocks. However, the second of these is the 150v shock, following which the learner demands to be released. As shown in extract 1c, the participant then begins a further attempt at disobeying the experimenter. At this point, it is notable that in the subsequent 
exchange the experimenter draws upon the visit to the learner as a rhetorical resource in order to attempt to elicit obedience from the teacher:

\section{Extract 1c (Participant 0208)}

59 L: Experimenter! Get me out of here! I won't be in

60 the experiment any more. I refuse to go on, let

$61 \quad$ me out!

62 E: $\quad$ Please continue.

63 T: Not under those conditions. Not with him

64 hollering.

65 E: I just checked on him, and he er, seemed pretty

66 willing to continue so please continue.

67 T: No not unless I think, you see he's hollering in

68 there it's just er

$69 \quad(16)$

70 E: It's absolutely essential that you continue.

71 T: Well I'm not gonna continue with the man

72 hollering that he wants to get out of there I mean

73 er (2) it might be essential to you but it's not that

$74 \quad$ essential for me.

75

(3)

76 E: I was just in there and he seemed willing enough

77 to continue.

78 T: Well, that's what he says but you know it's not

79 er

80 
81 E: $\quad(($ inaudible $))$

82 T: I mean i- I' $d$ be glad to walk in there if he says to

83 me go on I'll go on but I'm not going to go on

84 with the man hollering in there to stop.

85 E: You have no other choice you must go on.

86 T: Well I don't say that I mean I'm just not gonna go on

87 unless he says to go on.

88 E: Well we'll have to discontinue the experiment then.

The participant uses several rhetorical strategies here in order to bring the experiment to an end. Notably, he draws attention to the learner's 'hollering' (1. 64; 1. 67; 1. 72), as well as particularizing the experimenter's use of prod 3 by drawing a contrast between the experiment's importance for the experimenter and for himself (11. 73-4). Finally, he places a further condition on his continued participation to the effect that he will only continue if he can receive an assurance himself from the learner that he wishes to continue. However, of greater interest here are the rhetorical strategies employed by the experimenter, and specifically the way in which the supposed discussion between experimenter and learner is invoked in an attempt to elicit obedience (11. 65-6; 11. 76-7). It is instructive to consider this in greater detail.

The teacher's firm refusal to continue on 11. 63-4 is met with a novel rhetorical move by the experimenter, who mobilises his back-stage discussion to emphasise that the learner was apparently willing to continue. However, faced with the learner's demand to be released, this assertion is less clear-cut than it was in extract 1b. Although the experimenter emphasises the recency of the encounter (1. 65: I just checked on him...) as if to highlight the oddity of the learner's volte-face, his shift to the past tense (checked; seemed) allows for the learner's willingness to continue to be superseded by his present demand to be released. The 
participant again refuses, before a long silence ensues which is broken by the experimenter using prod 3 (1. 70). The participant then utilises the contrast between the experimenter's argument that the learner had seemed 'pretty willing to continue', and the learner's own demands to be released. Thus, the participant does not simply invoke the learner's 'hollering', but specifically his 'hollering that he wants to get of there' (1. 72).

The participant in this exchange successfully draws the experimental session to a close despite these departures from the experimenter's script. Nevertheless, the experimenter's excursion to apparently speak to the learner yielded two further shocks from the teacher before the learner's demand to be released galvanized the participant's argument to end the session. This exchange therefore demonstrates how both obedience and defiance can be understood as rhetorical processes. The participant seeks to provide arguments for why the experiment should be stopped, and the experimenter provides arguments for why the experiment must continue. The experimenter's arguments consist of a mixture of preprepared and improvised rhetorical strategies, and it is notable that the physical act of leaving the laboratory functions rhetorically as well, such that the persuasiveness of the experimenter is a joint function of both his physical and discursive actions.

The strategy of leaving the room was employed in two further experimental sessions in the data analysed for the present paper, eliciting two further shocks from participant 0219 , and seven further shocks from participant 0237. Although all three participants on whom the strategy was used were ultimately defiant, they nevertheless continued to administer shocks for longer than they might otherwise have done had the strategy not been used.

This analysis of 0208 's ultimately successful attempts at defiance draws attention to the rhetorical character of the experimenter's attempts to elicit obedience. The strategy of leaving the room ostensibly to speak to the learner may not be part of the standardized procedure as conveyed in Milgram's publications, but this is not to imply that it is only 
departures from standardization that function rhetorically. The pre-scripted prods can also be analysed for their rhetorical function, and in terms of the counter-arguments they elicited from participants.

You have no other choice...

While discussions of the obedience experiments routinely draw attention to the role of the experimenter's prods, there has as yet been no systematic attempt to explore how they were used in practice in the experimental sessions. For present purposes, I will focus on prod 4: 'You have no other choice, you must go on' (Milgram, 1974, p. 21, italics in original). This is significant for a number of reasons. First, it is the only one of the scripted prods to explicitly enlist the concept of choice. This is potentially important given the centrality of notions of autonomy and agency to Milgram's theoretical framework. Second, there are conflicting perspectives regarding whether we might expect this prod to have been particularly good at eliciting obedience. Referring to prod 4, Miller (2009, p. 25), has argued that, "[t]aken literally and out of context, these words are clearly preposterous. They violate any reasonable sense of ethics. In context, of course, they appear to have had considerable persuasive force'. It is notable that Miller suggests only that these words appear to have been so persuasive - no firmer statement is possible as there has yet to be empirical analysis at a detailed enough level to be able to establish whether the prod did indeed play such a key role in the elicitation of obedience.

In contrast, a recent analysis of the effectiveness of the four prods as used in Burger's (2009) partial replication of the Milgram paradigm suggests that the fourth prod may in fact be particularly ineffective at eliciting obedience (Burger et al., 2011). In Burger et al.'s analysis, no participants continued with the experimental procedure after having received the fourth prod. Burger et al suggest that this raises questions as to whether the Milgram 
paradigm can be said to be a demonstration of obedience. Similarly, Reicher and Haslam (2011, p. 167) suggest that 'the question of whether or not people obey this fourth prompt is decisive in establishing the validity of those interpretations of Milgram's studies that see them as a demonstration of how people follow orders.'

In an attempt to settle this debate, all uses of prod 4 in the transcripts from conditions 02 and 20 were identified. The first, and perhaps most striking, observation to note is just how ineffective prod 4 appears to have been. The prod was used for 23 participants across these two conditions, yet it occasioned further shocks from only two of these participants (one in each condition), only one of whom subsequently proceeded to be fully obedient (the other delivered only one further shock before successfully disobeying). Although it is of course possible that the prod was more effective in other experimental conditions, at the very least the suggestion that prod 4 had 'considerable persuasive force' (Miller, 2009, p.25) is challenged by further examination of the experimental interactions themselves in these two conditions.

This leads to the question of how precisely the participants resisted prod 4. In order to address this, it is worth considering some actual examples of the prod in use. As might be expected, participants responded to the experimenter's use of prod 4 in a variety of ways, but the most common $(\mathrm{N}=12)$ response was to employ a strategy of straightforward rhetorical negation. For example:

\section{Extract 2 (Participant 2032; 270v/225 ${ }^{3}$ )}

$1 \quad$ E: $\quad$ You have no other choice you must continue.

2 T: I have another choice. I won't continue.

3 E: Then we'll have to discontinue the, er, the experiment. 
The participant's assertion that she does indeed have a choice and will not continue simply dismisses the definition of the situation provided by the experimenter's use of prod 4.

Following the experimental procedure to the letter, the experimenter subsequently makes no further attempt to elicit obedience, and draws the experimental session to a close. By conceptualizing the experimenter's use of prod 4 as a rhetorical move, we can see how it in fact contains within it the very ingredients for its own refutation. Such a bald assertion of lack of choice tacitly makes available the powerful anti-logos of choice. Although this was the most straightforward version of this form of rebuttal, others used slightly more complex variations of it. Three participants combined their assertion of choice with an offer to return the cheque they had received for their participation. For example, consider the following exchange:

\section{Extract 3 (Participant 2036; 450v ${ }^{4}$ )}

1 E: You have no other choice you must [continue.]

2 T:

$[\mathrm{Oh} \mathrm{I}]$

3 certainly do have you can have your cheque back

4 sir.

5 E: No th- er, you, the cheque is yours simply for

6 coming to [the lab.]

7 T: $\quad[$ I don't] even care about that money I

8 don't need it that bad. And I'm not going on until

9 I know that man is all right. That's all

10 ((inaudible)) you go and look at him.

11 E: Well we'll have to discontinue the experiment. 
Here we see the experimenter use the assertion that the cheque is 'yours simply for coming to the lab' to frame the cheque as unimportant. The experimenter's use of this argument (though not officially part of the standardized script) was methodologically important as it allowed Milgram to rule out financial reward as a contributing factor in obedience. However, in the context of 2036's experimental session it also functions rhetorically to negate the participant's grounds for her 'choice'. This is met by the counter-assertion from the participant that the money is similarly unimportant to her, with a further argument which makes her continuation contingent on the establishment of the well-being of the learner (11. 89). It is only following this shift to a different rhetorical strategy that the experimenter discontinues the session.

Other participants $(\mathrm{N}=4)$ sought to engage the experimenter directly by asking for further justification of his assertion that they had 'no choice':

\section{Extract 4 (Participant 2005; 180v)}

1 E: You have no choice, really.

2 T: Why?

$3 \quad$ E: $\quad$ W-

$4 \quad$ T: $\quad$ You mean I can't get up and leave?

5 E: Certainly but I mean if you er, if you don't go on

6 we'll have to discontinue the entire, test you see.

7 T: Well, you can find someone else and do the same

8 thing over again. Well, I'm sorry.

9 E: Well we'll hav- it's all right. We'll have to

10 discontinue. 
It is notable that the experimenter's use of prod 4 here varies from the scripted version, and appears markedly weaker as a result. Specifically, the use of 'really' marks this not as a simple assertion of lack of choice, but as a contingent claim. The participant's questioning of the experimenter on lines 2 and 4 occasions a clarification from the experimenter that effectively retracts the 'no choice' prod by acknowledging that a choice is indeed available the participant can leave but this will result in the termination of the experiment. Even here, the experimenter employs a rhetorical device known as extreme case formulation (ECF; Pomerantz, 1986) in order to construct the results of discontinuation as particularly problematic - the consequence of the participant leaving is thus glossed as the discontinuation of 'the entire, test' (1. 6). This is mitigated by the participant, who suggests recruiting another participant and 'do[ing] the same thing over again' (11. 7-8).

This tactic of challenging the experimenter directly by demanding further explanation of his remarks essentially resulted in the modification or retraction of prod 4 , such that the experimenter weakened his rhetorical position as he went from a bald assertion that the participant had 'no choice', to an acknowledgement that they did indeed have a choice. This backtracking on the part of the experimenter is most starkly illustrated in participant 0228 's session:

\section{Extract 5 (Participant 0228; 300v) ${ }^{5}$}

1 E: You have no other choice you must go on.

2 T: Why? The man doesn't wa- I don't er, I don't want to do anymore, to the man, the man's yelling I can't er I can't take it. I don't like to hear anybody yell. That's how I am.

6 E: The experiment requires that you go on. Please 
7 continue.

9 T: $\quad$ Three hundred and fifteen volts.

10

11 T: Well what happens if I don't continue with this I

$12 \quad$ just walk out?

$13 \quad(2)$

14 E: That's your prerogative. But it is essential, that

15 you continue.

$16 \quad(3)$

17 E: $\quad$ Please continue.

18

19 T: No I- I- I- I- look I can't, I can't do it. I'm going

20 to have to go. I'm very sorry.

21 E: Well, we'll have to discontinue the experiment

The participant's initial question (1. 2: 'Why?') is followed by an argument against continuing which is predicated on the learner's refusal to continue and the participant's own character (11. 4-5: 'I can't take it. I don't like to hear anybody yell. That's how I am.'). On this occasion, the experimenter does not backtrack immediately, but instead uses prod 2. After a long gap of 21 seconds, the participant states the next voltage level to be administered (1. 9), but instead of delivering the shock he pauses again, and asks a further question concerning the consequences of him 'just walk[ing] out' (11. 11-12). Instead of denying the participant's choice, the experimenter's response on line 14 explicitly affirms that it is the participant's 'prerogative' to discontinue the experiment. He then uses a version of prod 3 
(11. 14-15: 'it is essential, that you continue'), and, following a pause, a further 'Please continue'. After another lengthy silence, the participant essentially exercises his 'prerogative' and states that he 'is going to have to go' (11. 19-20), at which point the session is discontinued.

When faced with prod 4, most participants therefore responded either by asserting that they did indeed have a choice, or by engaging with the experimenter in such a way that he ultimately acknowledged that they did have a choice. We can understand these interactions as rhetorical struggles over the definition of the situation, and over the definition of the participant's own psychological state. Prod 4 can therefore be understood as a logos which potentially makes available a powerful anti-logos, which participants were generally able to use: that in this situation they do have a choice.

\section{Concluding remarks}

The primary contribution of this approach to our understanding of the Milgram experiments is to draw attention to the importance of rhetoric in the interactions between experimenter and participant, with the experimenter essentially trying to argue the case for the continuation of the experiment, and the participant seeking to provide counter-arguments in favour of the cessation of the experimental session. To conclude, it is worth briefly discussing the implications of these observations for our understanding of the Milgram experiments.

The analysis raises questions about the meaning of obedience within discussions of the Milgram experiments. In highlighting the rhetorical nature of the experimenter's role in the experiments, the present analysis points to the intriguing possibility that the studies ultimately may have little to do with obedience as conventionally understood (see also Burger et al., 2011; Reicher \& Haslam, 2011). It is notable that the experimenter's responses to 
participants who appear reluctant to continue do not take the form of orders designed to elicit obedience, but are instead arguments designed to convince and persuade. Indeed, the most order-like interventions appear to have been overwhelmingly resisted. However, a further complicating factor arises from considering conversation analytic findings on requests and invitations (e.g. Drew, 1984; Kitzinger \& Frith, 1999). To suggest that people are only 'obeying' if the utterance which elicits their 'obedience' can be shown to be a grammatical 'order' may be problematic. Discursive actions (e.g. requests, invitations, refusals, etc.) are often made without formulating an utterance as a grammatical request, invitation, refusal, and so on. For example, a statement such as 'It's rather warm in here' can function as a request insofar as it is oriented to by those in the room as a request for a window to be opened.

Rather than suggesting that the Milgram experiments can no longer be seen as a demonstration of obedience, an alternative way of re-conceptualising them might therefore be to re-orient our understanding of obedience to incorporate actions elicited in the absence of a direct order. This would lead to the conclusion that Milgram's experimenter manages to elicit obedience without issuing direct orders, and that when direct orders are issued, obedience fails. Ultimately, however, this is an issue of analytic definition which risks neglecting the way in which terms such as 'obedience' might themselves be used rhetorically. An alternative perspective would be to topicalize invocations of 'obedience' as an object of analytic scrutiny themselves.

Such an analysis is beyond the scope of the present paper, but points to the need for further empirical work on this issue. It is nevertheless important to note that - whatever might or might not be said about what constitutes 'obedience' - the analysis presented here is suggestive of the failure of direct orders to elicit the participants' continuation with the experimental procedure. The analysis of the experimenter's fourth prod raises some interesting possibilities regarding the invocation of 'choice' and autonomy in the 
experiments. As noted above, Milgram's own theoretical framework conceptualized dis/obedience as a psychological tussle between individual autonomy and seeing the self as a vehicle for the agency of an authority figure (the agentic state). The present approach focuses instead on the way in which choice and related constructs were rhetorically negotiated by the protagonists in the experimental sessions themselves. This directs our attention to the way in which autonomy is as much a social discursive accomplishment as a private psychological object (Edwards \& Potter, 1992). As noted above, in framing the continuation of the experiment explicitly within a rhetorical strategy of (lack of) choice, prod 4 makes available a counter argument, or anti-logos, revolving around the capacity to exercise choice. In short, a useful alternative to theoretical debate concerning autonomy and agency in the Milgram experiments might be provided by attending to the ways in which the protagonists in the studies themselves argued about such matters. Whatever might, or might not, be said about underlying psychological states and processes, defiant participants were able to seize on the experimenter's invocation of choice as part of their rhetorical armoury to extricate themselves from the experiment.

This argument begs the question of why the counter-argument to prod four was seized upon so readily. It is instructive, if necessarily somewhat speculative, to relate these observations to western - and particularly US - discourses of individualism, which emphasise personal autonomy and freedom of choice (see e.g. Bauman, 2001; Sampson, 1993). In this respect, it is notable that the 'Professor of Old Testament' quoted by Milgram (1974) (see above) explicitly invokes his location in 'America' as grounds for resisting prod 4. As numerous authors have noted (e.g. Foucault, 1979; Rose, 1999), the subjects of capitalist liberal individualism are not governed through the direct administration of blunt disciplinary authority, but are instead shaped to become self-disciplining subjects. We might therefore suggest that, rather than providing a striking demonstration of the power of 
'obedience', Milgram's experiments are testament to the overwhelming failure of straightforward attempts to elicit 'obedience' in the face of powerful ideologies of autonomy. This is not, of course, to deny that the majority of participants in the conditions explored here did indeed proceed to the highest level of the shock generator, but to suggest that they did so without having to be compelled to do so by direct commands from the experimenter.

The reliance on transcripts made from audio recordings, borne out of necessity, raises an intriguing point about the nature of rhetoric itself. Specifically, rhetoric can be bodily as well as discursive. In extract $1 \mathrm{~b}$, the physical act of leaving the room, apparently to check the learner's willingness to continue, is just as much a rhetorical move as is the articulation of a discursive utterance. Similarly, the kinetic metaphor of the rhetorical move is apt here, as it is just as much a rhetorical move as it is a physical move - in order to convince, the experimenter's words must appear credible, and for this to be the case he must leave the room. In this sense, the present analysis points the way not only to a rhetorical perspective on the Milgram studies, but to the possibility of a widening of the scope of what we might understand as being rhetorical. Not only are words used to convince and persuade, but so too are physical actions. This resonates with recent attempts to draw attention to the neglect of embodiment in social psychology (e.g. Lyons \& Cromby, 2010; Potter \& Hepburn, 2008), and whilst the present paper is not the place to begin to flesh out the details of how such a perspective on rhetoric might further expand our view of the Milgram experiments, it is a potentially fruitful avenue for future research. For instance, Milgram (1974) noted that on many occasions participants initiated defiance not only by speaking, but by physically moving away from the table at which they were sitting whilst administering the learning test.

The analysis also has implications for our understanding of standardization in the Milgram experiments (see also Darley, 1995; Modigliani \& Rochat, 1995; Russell, 2009). It is striking that the rhetorical strategies employed by the experimenter depart sometimes quite 
substantially from the official experimental script. This is quite understandable given the problems inherent in trying to determine in advance the range of possible questions and challenges one might be faced with, but it does suggest that the conventional view of the experimental procedure as highly standardized needs to be revised. Even where the standard prods are used, they are not necessarily used in the correct order (e.g. extract 1a), or in the standard form (e.g. extract 4), and they sometimes contravene Milgram's (1974, p. 21) assertion that ' $[\mathrm{t}]$ he sequence was begun anew on each occasion that the subject balked or showed reluctance to follow orders' (e.g. extract 5).

In making these points, the aim is not to engage in methodological criticism and suggest that we can no longer treat Milgram's findings from these conditions as reliable because of the departures from standardization. Instead, it is my contention that these sometimes quite radical departures point to the importance of developing a perspective on Milgram's experiments - and indeed on dis/obedience more broadly - that is founded upon the rhetorical nature of encounters with authority. Moreover, in line with other recent reevaluations of Milgram's experiments, an engagement with the unfolding encounters between experimenter and participants points to the overwhelming ineffectiveness of direct orders in the experiments. As noted above, this may or may not be taken as evidence of the absence of 'obedience', but the wider point is that the issuing of orders simply did not work as a strategy for eliciting more electric shocks in the Milgram studies. That this has been obscured for almost fifty years should compel social psychologists to undertake a root-and-branch reevaluation of the 'obedience' experiments which places rhetoric and interaction centre-stage.

It should thus be apparent that any analysis that purports to present a complete account of dis/obedience but which fails to conceptualize the active rhetorical nature of language use is inherently limited, and moreover risks breaking down when specific instances of dis/obedience are scrutinized. In this respect, then, it does seem striking that the study of 
dis/obedience - and of the Milgram experiments in particular - has proceeded for so long without attention to language and rhetoric. The neglect of these issues within social psychology more generally perhaps goes some way towards explaining this lacuna, and so it is worth concluding by noting that the demonstrable importance of these issues within the Milgram experiments is suggestive of the need to address them more widely within the discipline as a whole. Discursive and rhetorical psychologists have long argued that the neglect of the active and constructive nature of language use in laboratory experimentation leaves the activities and findings of experimental psychology in need of re-interpretation. However, actual empirical analysis of language use in the psychological laboratory has been rare. If the meaning of one of social psychology's landmark studies undergoes such a profound transformation when issues of language and rhetoric are foregrounded, it should raise fundamental questions about the foundations of the discipline as a whole. 


\section{References}

Bauman, Z. (2001). The individualized society. Cambridge: Polity.

Benjamin, L. T., \& Simpson, J. A. (2009). The power of the situation: The impact of Milgram's obedience studies on personality and social psychology. American Psychologist, 64, 12-19. doi: 10.1037/a0014077

Billig, M. (1991). Ideology and opinion: Studies in rhetorical psychology. London: Sage. Billig, M. (1996). Arguing and thinking: A rhetorical approach to social psychology (2 ${ }^{\text {nd }}$ ed.). Cambridge: Cambridge University Press.

Billig, M. (1999). Whose terms? Whose ordinariness? Rhetoric and ideology in conversation analysis. Discourse and Society, 10, 543-558. doi: $10.1177 / 0957926599010004005$

Billig, M., Condor, S., Edwards, D., Gane, M., Middleton, D., \& Radley, A. (1988). Ideological dilemmas: A social psychology of everyday thinking. London: Sage.

Blass, T. (2004). The man who shocked the world: The life and legacy of Stanley Milgram. New York: Basic Books.

Blass, T. (2009). From New Haven to Santa Clara: A historical perspective on the Milgram obedience experiments. American Psychologist, 64, 37-45. doi: 10.1037/a0014434

Burger, J. M. (2009). Replicating Milgram: Would people still obey today? American Psychologist, 64, 1-11. doi: 10.1037/a0010931

Burger, J. M., Girgis, Z. M., \& Manning, C. M. (2011). In their own words: Explaining obedience to authority through an examination of participants' comments. Social Psychological and Personality Science, 2, 460-466. doi: 10.1177/1948550610397632

Dambrun, M., \& Vatiné, E. (2010). Reopening the study of extreme social behaviors:

Obedience to authority within an immersive video environment. European Journal of Social Psychology, 40, 760-773. doi: 10.1002/ejsp.646 
Darley, J. M. (1995). Constructive and destructive obedience: A taxonomy of principalagent relationships. Journal of Social Issues, 51, 125-154. doi: 10.1111/j.15404560.1995.tb01338.x

De Vos, J. (2009). Now that you know, how do you feel? The Milgram experiment and psychologization. Annual Review of Critical Psychology, 7, 223-246. Retrieved from http://www.discourseunit.com/arcp/arcp7/arcp7devos.doc

Drew, P. (1984). Speakers' reportings in invitation sequences. In J. M. Atkinson \& J. Heritage (Eds), Structures of social action: Studies in conversation analysis. Cambridge: Cambridge University Press.

Edwards, D., \& Potter, J. (1992). Discursive psychology. London: Sage.

Fiske, S. T., Harris, L. T., \& Cuddy, A. J. C. (2004). Why ordinary people torture enemy prisoners. Science, 306, 1482-1483. doi: 10.1126/science.1103788

Foucault, M. (1979). Discipline and punish: The birth of the prison. London: Penguin.

Gilbert, G. N. \& Mulkay, M. (1984). Opening Pandora's box: A sociological analysis of scientists' discourse. Cambridge: Cambridge University Press.

Haslam, S. A., \& Reicher, S. (2007). Beyond the banality of evil: Three dynamics of an interactionist social psychology of tyranny. Personality and Social Psychology Bulletin, 33, 615-622. doi: 10.1177/0146167206298570

Kitzinger, C. \& Frith, H. (1999). Just say no? The use of conversation analysis in developing a feminist perspective on sexual refusal. Discourse \& Society, 10, 293 316. doi: 10.1177/0957926599010003002

Kroger, R. O., \& Wood, L. A. (1998). The turn to discourse in social psychology. Canadian Psychology, 39, 266-279. doi: 10.1037/h0086818 
Lankford, A. (2009). Promoting aggression and violence at Abu Ghraib: The U.S. military's transformation of ordinary people into torturers. Aggression and Violent Behavior, 14, 388-395. doi: 10.1016/j.avb.2009.06.007

Lyons, A. C. \& Cromby, J. (2010). Social psychology and the empirical body: Rethinking the relationship. Social and Personality Psychology Compass, 4, 1-13. doi: 10.1111/j.1751-9004.2009.00219.x

Madill, A., \& Gough, B. (2008). Qualitative research and its place in psychological science. Psychological Methods, 13, 254-271. doi: 10.1037/a0013220

Milgram, S. (1963). Behavioral study of obedience. Journal of Abnormal and Social Psychology, 67, 371-378. doi: 10.1037/h0040525

Milgram, S. (1965a). Some conditions of obedience and disobedience to authority. Human Relations, 18, 57-76. doi: 10.1177/001872676501800105

Milgram, S. (Producer). (1965b). Obedience [DVD]. Available from PennState Media Sales, http://www.mediasales.psu.edu

Milgram, S. (1974). Obedience to authority: An experimental view. New York: Harper \& Row.

Miller, A. G. (1986). The obedience experiments: A case study of controversy in social science. New York: Praeger.

Miller, A. G. (2004). What can the Milgram experiments tell us about the Holocaust? Generalizing from the social psychology laboratory. In A. G. Miller (Ed.), The social psychology of good and evil (pp. 193-239). New York: Guilford Press.

Miller, A. G. (2009). Reflections on "Replicating Milgram" (Burger, 2009). American Psychologist, 64, 20-27. doi: 10.1037/a0014407 
Miller, A. G., Collins, B. E., \& Brief, D. E. (1995). Perspectives on obedience to authority: The legacy of the Milgram experiments. Journal of Social Issues, 51, 1-19. doi: 10.1111/j.1540-4560.1995.tb01331.x

Modigliani, A., \& Rochat, F. (1995). The role of interaction sequences and the timing of resistance in shaping obedience and defiance to authority. Journal of Social Issues, 51, 107-123. doi: 10.1111/j.1540-4560.1995.tb01337.x

Nissani, M. (1990). A cognitive reinterpretation of Stanley Milgram's observations on obedience to authority. American Psychologist, 45, 1384-1385. doi: 10.1037/0003066X.45.12.1384

Packer, D. J. (2008). Identifying systematic disobedience in Milgram's obedience experiments: A meta-analytic review. Perspectives on Psychological Science, 3, 301-304. doi: 10.1111/j.1745-6924.2008.00080.x

Parker, I. (2007). Revolution in psychology: Alienation to emancipation. London: Pluto.

Passini, S., \& Morselli, D. (2009). Authority relationships between obedience and disobedience. New Ideas in Psychology, 27, 96-109. doi: 10.1016/ j.newideapsych.2008.06.001

Pomerantz, A. (1986). Extreme case formulations: A way of legitimizing claims. Human Studies, 9, 219-229. doi: 10.1007/BF00148128

Potter, J. (1996). Representing reality: Discourse, rhetoric and social construction. London: Sage.

Potter, J. (2007). Discourse and psychology (Vols. 1-3). London: Sage.

Potter, J. \& Hepburn, A. (2008). Discursive constructionism. In J. A. Holstein \& J. F. Gubrium (Eds.), Handbook of constructionist research (pp. 275-293). New York: Guilford Press. 
Potter, J. \& Wetherell, M. (1987). Discourse and social psychology: Beyond attitudes and behaviour. London: Sage.

Reeder, G. D., Monroe, A. E., \& Pryor, J. B. (2008). Impressions of Milgram's obedient teachers: Situational cues inform inferences about motives and traits. Journal of Personality and Social Psychology, 95, 1-17. doi: 10.1037/0022-3514.95.1.1

Reicher, S. \& Haslam, S. A. (2011). After shock? Towards a social identity explanation of the Milgram ‘obedience’ studies. British Journal of Social Psychology, 50, 163-169. doi: $10.1111 / \mathrm{j} .2044-8309.2010 .02015 . \mathrm{x}$

Rennie, D. L., Watson, K. D., \& Monteiro, A. M. (2002). The rise of qualitative research in psychology. Canadian Psychology, 43, 179-189. doi: 10.1037/h0086914

Rose, N. (1999). Powers of freedom: Reframing political thought. Cambridge: Cambridge University Press.

Russell, N. J. C. (2009). Stanley Milgram's obedience to authority experiments: Towards an understanding of their relevance in explaining aspects of the Nazi Holocaust (Doctoral dissertation, Victoria University of Wellington). Retrieved from: http://researcharchive.vuw.ac.nz/handle/10063/1091

Russell, N. J. C. (2011). Milgram's obedience to authority experiments: Origins and early evolution. British Journal of Social Psychology, 50, 140-162. doi: 10.1348/014466610x492205

Sampson, E. E. (1993). Celebrating the other: A dialogic account of human nature. New York: Harvester Wheatsheaf.

Schegloff, E. A. (1997). Whose text? Whose context? Discourse \& Society, 8, 165-187. doi: $10.1177 / 0957926597008002002$

Schegloff, E. A. (1998). Reply to Wetherell. Discourse and Society, 9, 413-416. doi: 10.1177/0957926598009003006 
Schegloff, E. A. (1999). Naivete vs sophistication or discipline vs self-indulgence: A rejoinder to Billig. Discourse and Society, 10, 577-582. doi: $10.1177 / 0957926599010004008$

Wetherell, M. (1998). Positioning and interpretative repertoires: Conversation analysis and post-structuralism in dialogue. Discourse and Society, 9, 387-412. doi: $10.1177 / 0957926598009003005$ 


\section{Footnotes}

\footnotetext{
${ }^{1}$ Milgram (1974) re-numbered some of his experimental conditions, including 'Women as Subjects',
} which became condition 8 . In order to ensure consistency with the archival material, the present article uses Milgram's original numbering, which appears to be ordered chronologically, in which this is condition 20.

${ }^{2}$ In the excerpts from these transcripts presented below, speakers are identified as E (Experimenter), T (Teacher) and L (Learner). Other transcription conventions are as follows:

((inaudible)) Double parentheses indicate comments from the transcriber. Numbers in parentheses indicate a timed silence, with the number indicating the amount in seconds.

URGH! Capitals indicate utterances that are noticeably louder than the surrounding talk. Exclamation marks indicate increased urgency in the delivery of the utterance.

I can't, I A comma indicates a pause of less than a second.

I- $\quad$ A dash indicates a sharp cut-off of the preceding utterance.

[continue] Brackets indicate overlapping talk.

volts. A full-stop (period) indicates a 'stopping' intonation, rather than the end of a grammatical sentence per se.

Why? A question mark indicates a questioning intonation, rather than a grammatical question per se.

${ }^{3}$ According to participant 2032's file in the archives, she had administered the punishments as instructed up to the $270 \mathrm{v}$ shock level, but had then administered three further shocks of, respectively, 15v, 120v and $225 \mathrm{v}$. The last shock administered was therefore $225 \mathrm{v}$, although a shock of $270 \mathrm{v}$ had previously been administered.

${ }^{4}$ The experimental procedure allowed for participants to deliver the $450 \mathrm{v}$ shock three times, at which point the experimenter would draw the experimental session to a close if the participant had not successfully disobeyed. Participant 2036 disobeyed having already delivered one 450v shock. As an aside, it is worth noting that this contradicts Milgram's (1974, p. 206) assertion that ' $[n]$ o subject who reached the $30^{\text {th }}$ shock level ever refused to continue using it.' This discrepancy possibly arises from a mislabelling of the archived file for 2036, which seems in fact to refer to a pilot participant who was fully obedient and therefore administered the 450v shock three times. 


\footnotetext{
${ }^{5}$ It is worth noting that prod 4 here follows a renewed attempt at defiance by this participant, and whereas prods 1-3 had been used during an earlier attempt to break-off from the experiment, the participant had subsequently gone on to administer three more shocks. This therefore constitutes a new attempt to break-off, and prod 4 is thus the first prod used in this sequence. This experimental session therefore appears to contradict Milgram's (1974, p. 21) assertion that the series of prods 'was begun anew on each occasion that the subject balked or showed reluctance to follow orders'.
} 